\title{
Vastus Intermedius Muscle
}

National Cancer Institute

\section{Source}

National Cancer Institute. Vastus Intermedius Muscle. NCI Thesaurus. Code C117876.

The portion of the quadriceps femoris muscle group that is underneath the Rectus Femoris muscle, spans and covers the upper two-thirds of the anterior and lateral surfaces of the femur, and inserts into the lateral border of the patella. 